\title{
Gastrointestinal Stromal Tumors: A Clinicopathological and Immunohistochemical Study of 65 Cases
}

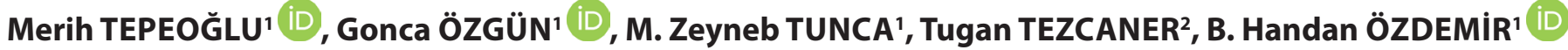 \\ Department of 'Pathology and ${ }^{2}$ General Surgery, Başkent University Faculty of Medicine, ANKARA, TURKEY
}

\begin{abstract}
Objective: The clinical behavior of gastrointestinal stromal tumors is divergent. The aim of the present study was to define the clinicopathological features that determine the patient's outcome.
\end{abstract}

Material and Method: Sixty-five gastrointestinal stromal tumors were reviewed with their histological, immunohistochemical and clinical features and compared with their clinical outcome statistically.

Results: Tumors were located in the stomach $(\mathrm{n}=39,60 \%)$, small intestine $(\mathrm{n}=22,33.8 \%)$ and large intestine $(\mathrm{n}=4,6.2 \%)$. Immunohistochemically, CD 117 positivity was found in 90.8\%, whereas CD34, Smooth muscle actin, Desmin and S100 positivity was found in $73.3 \%, 61.7 \%, 11.7 \%$ and $28.3 \%$ of tumors respectively. All six "CD 117-negative" cases expressed DOG-1. The mean Ki-67 proliferation index was $8.69 \% \pm 12.76$. Liver metastasis was detected in seven cases. A significant association was detected between decreased mean survival time and increased tumor size $(\mathrm{p}<0.001)$, large bowel localization $(\mathrm{p}=0.047)$, mitosis $(\mathrm{p}<0.001)$, the presence of necrosis $(\mathrm{p}=0.001)$, metastasis $(\mathrm{p}=0.033), \mathrm{Ki}-67 \mathrm{proliferation}$ index $(\mathrm{p}=0.002)$ and risk category $(\mathrm{p}<0.001)$. CD 34 positivity was mostly seen in the stomach $(\mathrm{p}=0.001)$, and CD 34 positive tumors had longer overall survival (92.85. \pm 5.77 months versus $67.21 \pm 13.68$ months) ( $\mathrm{p}=0.046)$. Higher Ki-67 proliferation index $(\geq 6 \%)$ was also correlated with the presence of metastases $(\mathrm{p}=0.015)$.

Conclusion: Our study indicates that in addition to well-known risk factors such as increased tumor size, high mitotic activity and metastasis; higher Ki-67 proliferation index, the presence of necrosis, and CD34 negativity also correlate with shorter survival time.

Key Words: Gastrointestinal stromal tumors, Necrosis, Ki-67, CD-34

\section{INTRODUCTION}

Gastrointestinal stromal tumors (GISTs) are the most common mesenchymal tumors of the digestive tract. GISTs can occur at every level of the gastrointestinal tract, but most commonly in the stomach (60-70\%), and small intestine (20-30\%). Rarely, they can be seen in extragastrointestinal locations, like the omentum, retroperitoneum, and mesentery (1-7). GISTs occur by neoplastic transformation of the interstitial cell of Cajal, the mesenchymal derived intestinal pacemaker cells (1-4). These cells specifically express the tyrosine kinase receptor c-kit (CD 117). Although several GISTs show strong histomorphological similarities, they have different immunophenotypes and biological behavior, and this diversity yields various confusing data in the literature (1-7). The purpose of this study was to determine the clinicopathologic features of 65 GISTs and reveal the pathological factors that negatively influence overall survival.

\section{MATERIAL and METHODS}

A total of 65 cases that were diagnosed as GIST at Baskent University, Department of Pathology between January 2003

(Turk Patoloji Derg 2018, 34:207-214)

Received : 28.07.2017 Accepted : 12.03.2018 and April 2016 and having survival data were included in the study. The study protocol was approved by the local Ethics Committee of the University Hospital. Each case was reviewed for tumor localization, tumor size, predominant cell type, mitotic activity/50 high power fields (HPF), the presence of coagulative necrosis, and Ki-67 proliferation rate. Mitoses were counted in the most cellular areas. All cases were immunohistochemically stained with CD 117, Smooth muscle actin (SMA), Desmin, S100, and CD 34. Additionally DOG1 (discovered on GIST-1) was used in CD 117 negative cases. The staining pattern of CD 117 was considered as diffuse if the number of positive cells was $\geq 50 \%$ and focal if $<50 \%$. The staining intensity was evaluated as mild or intense. Clinical data and follow-up information was obtained from medical records. The risk stratification of GISTs classification was evaluated according to the Armed Forces Institute of Pathology (AFIP) classification (Miettinen and Lasota criteria) Accordingly, tumors were classified as very low-risk, low-risk, intermediate risk or high-risk, based on tumor localization (stomach/jejunum or ileum/duodenum/rectum), mitotic rate $(\leq 5 / 50 \mathrm{HPF}$ or $>5 / 50 \mathrm{HPF})$ and tumor size $(\leq 2 \mathrm{~cm},>2-\leq 5 \mathrm{~cm},>5-\leq 10 \mathrm{~cm}$ and $>10 \mathrm{~cm})(2-5)$.

Correspondence: Merih TEPEOĞLU

Department of Pathology, Başkent University Faculty of Medicine, Bahçelievler 06490, ANKARA, TURKEY

E-mail: merihdemirel@yahoo.com.tr Phone: +90 3122126591 
Statistical analysis of the data was done with SPSS for Windows 13.0 statistical package software. Demographic variables were detected by descriptive statistics. Standard error of mean was presented in parametric values while standard deviation was used in non-parametric values. Categorical data were examined using the Chi-square test. Pearson's Chi-square and Fisher's exact tests were used to assess the association between categorical variables. The statistical comparison of the median values of groups was done by the Mann-Whitney $\mathrm{U}$ and Kruskal-Wallis tests. The Kaplan-Meier method was used to determine the disease-free survival rate. Survival curves between two categories were compared using a Log-rank test. A p value $<0.05$ was required for statistical significance.

\section{RESULTS}

The patient group included 34 women (52.3\%) and 31 men $(47.7 \%)$ whose ages ranged from 24 to 93 years (mean, $61.75 \pm 15.77$ years). The most common symptom was abdominal pain (68.4\%), followed by abdominal mass (22.2\%). Among 65 patients, $26(40 \%)$ underwent complete surgical resection and $39(60 \%)$ underwent segmental resection or excision. After surgery, 30 (46.1\%) patients had imatinib therapy. Thirty-nine $(60 \%)$ tumors were localized in the stomach, while $22(33.8 \%)$ were in the small and $4(6.2 \%)$ were in the large intestine. The size of tumor ranged between $0.5 \mathrm{~cm}$ and $37 \mathrm{~cm}$, with a mean of $6.5 \pm 5.7 \mathrm{~cm}$. The mean number of mitoses were $4.21 \pm 7.06$ (Minimum: 0-maximum: 50/50 HPF). Metastasis was seen in $7(8.6 \%)$ patients with the metastatic site being the liver in each case. Clinicopathological parameters of all 65 cases are shown in Table I.

Morphologically, 44 cases $(67.7 \%)$ had pure spindle cell morphology, while 2 (3.1\%) had pure epithelioid cell and 19 (29.2\%) had mixed morphology. Immunohistochemically,

Table I: Clinicopathological characteristics with mean survival months of 65 cases with GISTs.

\begin{tabular}{|c|c|c|c|}
\hline Characteristics & Number of patients (\%) & $\begin{array}{c}\text { Overall survival } \\
\text { (months } \pm \text { Std.Error of Mean) }\end{array}$ & $\begin{array}{c}\text { P value } \\
\text { (Overall survival) }\end{array}$ \\
\hline \multicolumn{4}{|c|}{ Gender } \\
\hline Male & $31(47.7)$ & $90 \pm 8.11$ & \multirow{2}{*}{$\mathrm{p}=0.739$} \\
\hline Female & $34(52.3)$ & $86.3 \pm 7.36$ & \\
\hline \multicolumn{4}{|c|}{ Tumor localization } \\
\hline Stomach & $39(60)$ & $98.1 \pm 5.72$ & \multirow{3}{*}{$\mathrm{p}=\mathbf{0 . 0 4 7}$} \\
\hline Small intestine & $22(33.8)$ & $77.6 \pm 10.37$ & \\
\hline Large intestine & $4(6.2)$ & $56.5 \pm 26.66$ & \\
\hline \multicolumn{4}{|c|}{ Tumor size } \\
\hline$\leq 2 \mathrm{~cm}$ & $5(7.7)$ & $120 \pm 0$ & \multirow{4}{*}{$\mathrm{p}<0.001$} \\
\hline$>2-\leq 5 \mathrm{~cm}$ & $28(43.1)$ & $114.7 \pm 5.67$ & \\
\hline$>5-\leq 10 \mathrm{~cm}$ & $23(35.4)$ & $66 . \pm 9.14$ & \\
\hline$>10 \mathrm{~cm}$ & $9(13.8)$ & $62.3 \pm 6.27$ & \\
\hline \multicolumn{4}{|c|}{ Mitotic count } \\
\hline$\leq 5 / 50 \mathrm{HPF}$ & $52(80)$ & $97.3 \pm 5.30$ & \multirow{2}{*}{$\mathrm{p}<0.001$} \\
\hline$>5 / 50 \mathrm{HPF}$ & $13(20)$ & $55.3 \pm 12.4$ & \\
\hline \multicolumn{4}{|c|}{ Ki-67 proliferation index } \\
\hline$<6 \%$ & $43(66.2)$ & $99.8 \pm 6.15$ & \multirow{2}{*}{$\mathrm{p}=\mathbf{0 . 0 0 2}$} \\
\hline$\geq 6 \%$ & $22(33.8)$ & $65.1 \pm 8.62$ & \\
\hline \multicolumn{4}{|c|}{ Necrosis } \\
\hline Present & $18(27.7)$ & $62.3 \pm 9.96$ & \multirow{2}{*}{$\mathrm{p}=\mathbf{0 . 0 0 1}$} \\
\hline Absent & $47(72.3)$ & $99.3 \pm 5.67$ & \\
\hline \multicolumn{4}{|c|}{ Cell type } \\
\hline Spindle & $44(67.7)$ & $93.6 \pm 6.47$ & \multirow{3}{*}{$\mathrm{p}=0.355$} \\
\hline Epithelioid & $2(3.1)$ & $74.5 \pm 44.5$ & \\
\hline Mixed & $19(29.2)$ & $77.38 \pm 9.97$ & \\
\hline \multicolumn{4}{|c|}{ Metastasis } \\
\hline Present & $6(9.2)$ & $54 \pm 11.5$ & \multirow{2}{*}{$\mathrm{p}=\mathbf{0 . 0 3 3}$} \\
\hline Absent & $59(90.8)$ & $91.9 \pm 5.66$ & \\
\hline \multicolumn{4}{|c|}{ Risk Category (AFIP) } \\
\hline Very low risk & $24(36.9)$ & $115.6 \pm 4.24$ & \multirow{4}{*}{$\mathrm{p}<0.001$} \\
\hline Low risk & $17(26.2)$ & $102.2 \pm 9.17$ & \\
\hline Intermediate risk & $7(10.8)$ & $60 \pm 16.1$ & \\
\hline High risk & $17(26.2)$ & $56.1 \pm 8.76$ & \\
\hline
\end{tabular}


CD117 positivity was detected in $59(90.8 \%)$ of 65 . The staining pattern was diffuse in 43 patients $(66.2 \%)$, while it was focal in 16 patients (24.6\%). Density of staining was intense in 38 patients (58.5\%) and mild in 21 patients (32.3\%). No statistical significance was found between the CD 117 staining pattern or density with tumor localization or the other clinicopathological parameters. All of the six CD 117 negative cases showed DOG1 positivity and 4 of them were also positive for CD 34 and SMA. The distribution of expression of immunohistochemical findings according to localizations is shown in Table II. A statistically significant association was found in CD 34 expression between stomach and non-stomach tumors. CD 34 positivity was mostly seen in stomach tumors $(\mathrm{p}=0.001)$; however, there were no statistically significant associations between CD 117, SMA, desmin and S100 expression and localization ( $\mathrm{p}>0.05)$. The mean Ki-67 proliferation index was $8.69 \pm 12.76 \%$ (Range: $1 \%$ to $65 \%$ ). The cases of intestinal and gastric GISTs with morphological and immunohistochemical findings are shown in Figure 1A-E and Figure 2A-E respectively.

Statistically significant associations were also detected between risk category and, the presence of necrosis $(\mathrm{p}=0.001)$, Ki-67 proliferation index $(\mathrm{p}=0.002)$ and the presence of metastasis $(\mathrm{p}=0.005)$. With increasing risk category, the presence of necrosis and metastasis, were found to increase. Ki-67 proliferation was also found to be highest in the high-risk category ( $\mathrm{p}=0.002$ ). However no statistically significant association was observed between risk category and tumor cell type $(\mathrm{p}=0.24)$, expression of CD $117(\mathrm{p}=0.89)$, SMA $(\mathrm{p}=0.49)$, Desmin $(\mathrm{p}=0.82)$, CD $34(\mathrm{p}=0.09)$ and S $100(\mathrm{p}=0.90)$.
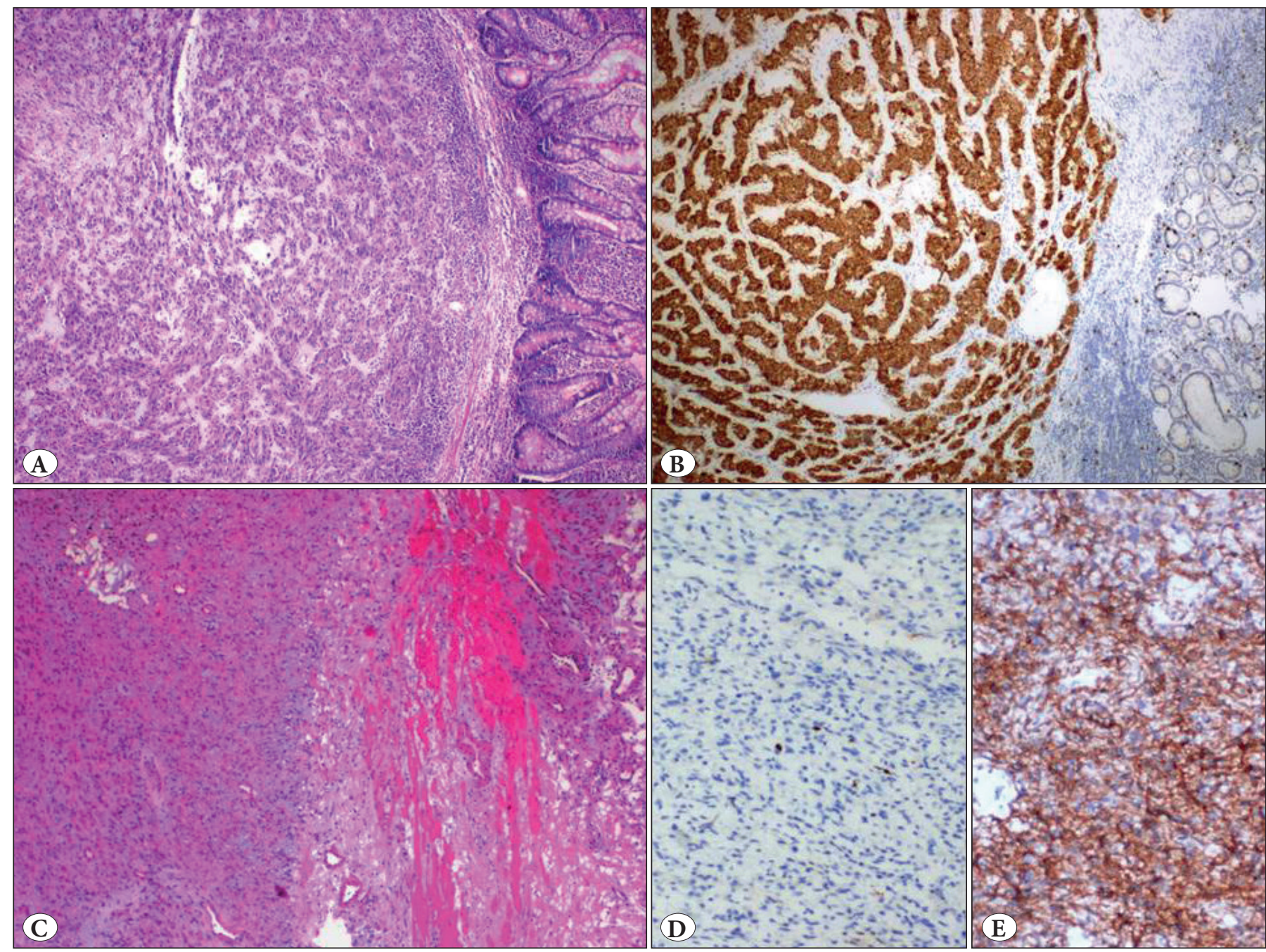

Figure 1: A) A case of intestinal stromal tumor, that is localized in submucosa (H\&E; x40). B) Diffuse CD 117 positivity in this case (IHC; $\mathrm{x} 40$ ). C) GIST with epithelioid morphology in the small intestine (H\&E; x40). D) CD 117 is negative in this case. Note that the infiltrating mast cells are positive with CD 117 (IHC; x100). E) Tumor cells show diffuse membranous and cytoplasmic positivity for DOG1 (IHC; $\mathrm{x} 100)$. 
Table II: The expression of immunohistochemical markers according to localizations.

\begin{tabular}{cccccc}
\hline \multicolumn{2}{c}{ Immunohistochemical panel } & Stomach & Small intestine & Large intestine & Total \\
\hline \multirow{2}{*}{ CD 117 } & Positive & $36(92.3 \%)$ & $20(90.9 \%)$ & $3(75 \%)$ & $59(90.8 \%)$ \\
\cline { 2 - 5 } & Negative & $3(7.7 \%)$ & $2(9.1 \%)$ & $1(25 \%)$ & $6(9.2 \%)$ \\
\hline \multirow{2}{*}{ CD34 } & Positive & $32(91.4 \%)$ & $12(57.1 \%)$ & $0(0 \%)$ & $44(73.3 \%)$ \\
\cline { 2 - 5 } & Negative & $3(8.6 \%)$ & $9(42.9 \%)$ & $4(100 \%)$ & $16(26.7 \%)$ \\
\hline \multirow{2}{*}{ SMA } & Positive & $19(54.3 \%)$ & $15(71.4 \%)$ & $3(75 \%)$ & $37(61.7 \%)$ \\
\cline { 2 - 5 } & Negative & $16(45.7 \%)$ & $6(28.6 \%)$ & $1(25 \%)$ & $23(38.3 \%)$ \\
\hline \multirow{2}{*}{ S100 } & Positive & $8(22.9 \%)$ & $6(28.6 \%)$ & $3(75 \%)$ & $17(28.3 \%)$ \\
\cline { 2 - 5 } & Negative & $27(77.1 \%)$ & $15(71.4 \%)$ & $1(25 \%)$ & $43(71.7 \%)$ \\
\hline \multirow{2}{*}{ Desmin } & Positive & $5(14.3 \%)$ & $1(4.8 \%)$ & $1(25 \%)$ & $7(11.7 \%)$ \\
\cline { 2 - 5 } & Negative & $30(85.7 \%)$ & $20(95.2 \%)$ & $3(75 \%)$ & $53(88.3 \%)$ \\
\hline
\end{tabular}
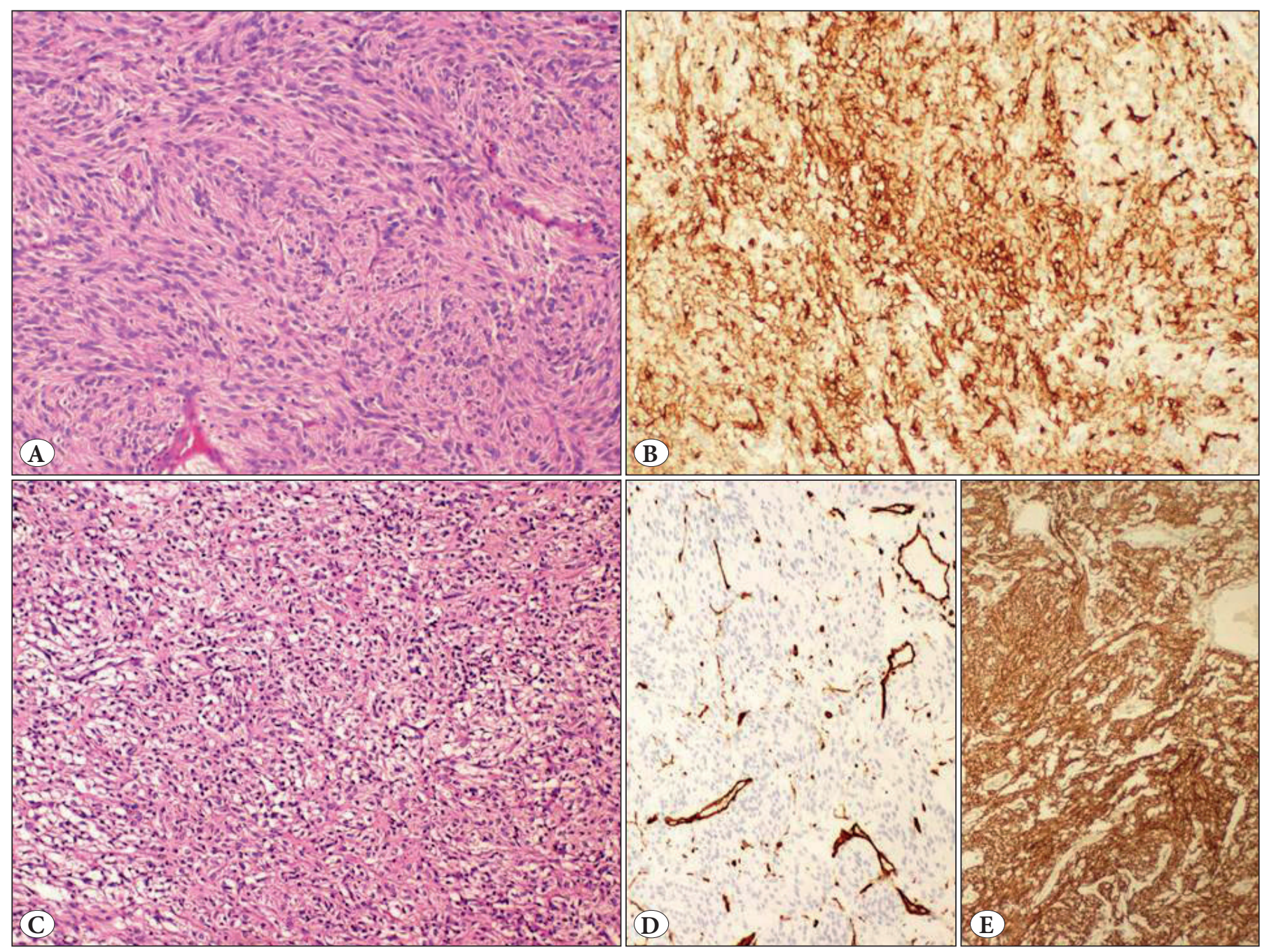

Figure 2: A) A case of gastric GIST with spindle cell morphology is seen (H\&E; x40). B) CD 34 positivity is seen in this case (IHC; $x 100)$. C) A case of gastric GIST with epithelioid cell morphology is shown (H\&E; x40). D) Tumor cells are negative for CD 34, whereas vascular channels as internal control are positive for CD 34 (IHC; x100). E) Tumor cells show diffuse membranous and cytoplasmic positivity for DOG1 (IHC; x100). 
With increasing tumor size, the presence of metastasis was also increased $(\mathrm{p}=0.011)$. Both high mitotic index values $(>5 / 50 \mathrm{HPF})$ and high Ki-67 proliferation index $(\geq 6 \%)$ were correlated with the presence of metastases $(\mathrm{p}=0.08$, $\mathrm{p}=0.015$ respectively).

\section{Survival Analysis}

The mean follow-up time for the 65 patients was $88.05 \pm 41.5$ months (range 1 to 152 months). Throughout the followup period, 15 of 65 patients (23.1\%) died at a mean time of $57.83 \pm 42.1$ months (range 1 to 121 months). Cause of death in all of these patients was related to disease recurrence with $10(66.7 \%)$ having a tumor located in the stomach, $3(20 \%)$ in the small intestine and $2(13.3 \%)$ in the large intestine. The remaining 50 patients $(76.9 \%)$ were living without recurrence for a mean period of 95.76. \pm 38.1 months. The relationship between the clinicopathological findings of 65 patients and their prognoses is given in Table I.

Univariate analysis demonstrated that large bowel localization in the gastrointestinal site $(\mathrm{p}=0.047)$, tumor size larger than $5 \mathrm{~cm}(\mathrm{p}<0.001)$, mitotic count higher than $5 / 50$ HPF $(\mathrm{p}<0.001), \mathrm{Ki}-67$ proliferation index equal to or higher than $6 \%(\mathrm{p}=0.002)$, the presence of necrosis $(\mathrm{p}=0.001)$, and the presence of metastasis $(\mathrm{p}=0.033)$ indicated shorter overall survival than their corresponding groups.

No significant correlation was seen between overall survival and gender $(\mathrm{p}=0.739)$, and tumor cell type $(\mathrm{p}=0.355)$, although patients whose tumors included an epithelioid cell type had shorter mean survival time than patients who did not (Table I). No significant correlation was found between mean survival and CD 117, SMA, Desmin and S100 immunoreactivity ( $\mathrm{p}=0.909,0.661,0.791$, 0.561 respectively). However, a significant association was detected between CD 34 expression and survival ( $p=0.046$ ), in that patients with CD 34 positive tumors had longer overall survival than those with CD 34 negative tumors (survival time was $92.85 \pm 5.77$ months in CD 34 positive tumors versus $67.21 \pm 13.68$ months in $\mathrm{CD} 34$ negative cases).

Kaplan-Meier analysis revealed that 3, 5 and 10-year overall survival rates were respectively $90 \%, 80 \%$, and $78 \%$ in our patients. 10 -year overall survival was $86 \%$ in patients with $<5 \mathrm{~cm}$ tumor size and $61 \%$ in those with $\geq 5 \mathrm{~cm}$ tumor size $(\mathrm{p}=0.017)$. While 10 -year overall survival in patients who had $\leq 5$ mitoses per $50 \mathrm{HPF}$ was $80.8 \%$, it was $69 \%$ in those who had $>5$ mitoses $/ 50$ HPF ( $\mathrm{p}=0.332$ ). As for Ki-67 proliferation, 10 -year overall survival was $84 \%$ for patients rated $<6 \%$ and $65 \%$ for those rated $\geq 6 \%(p=0.064)$. KaplanMeier plots are given in Figure 3A-C.
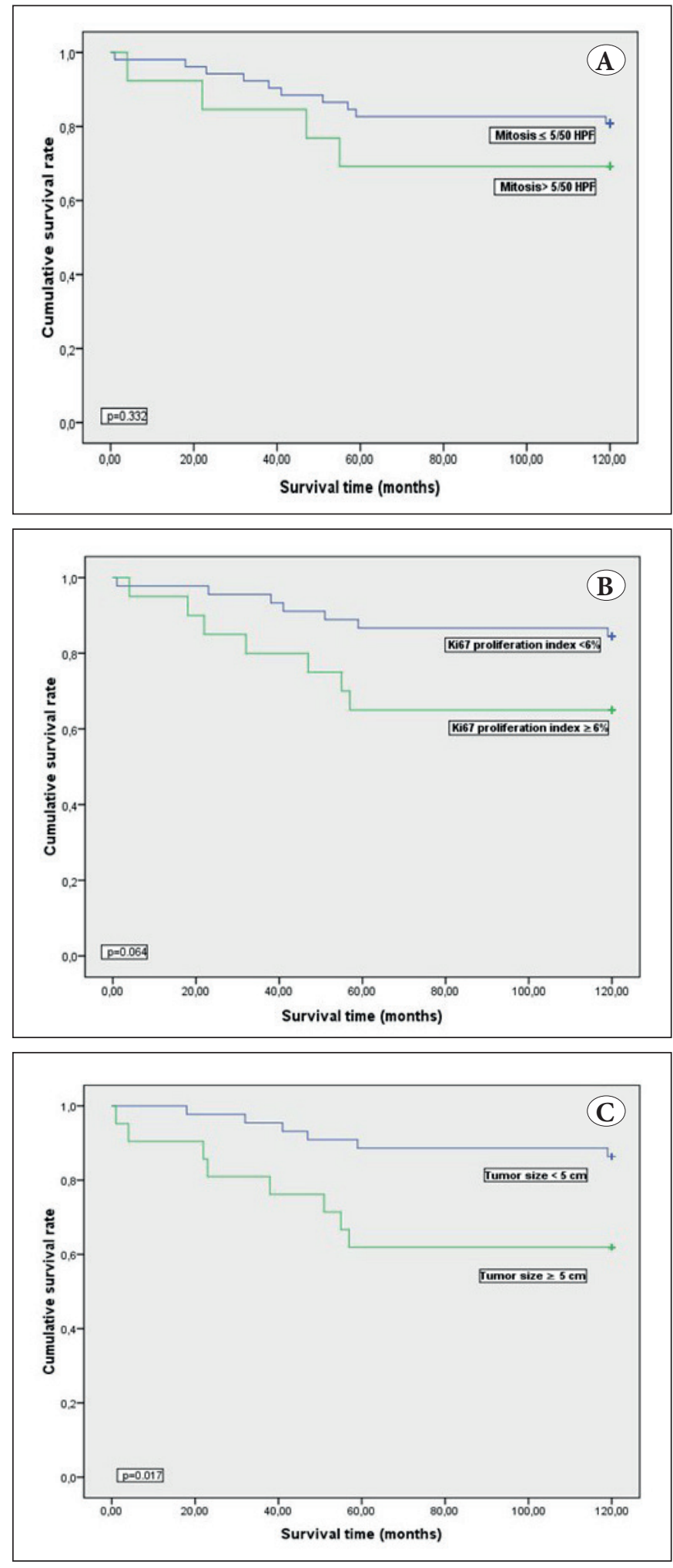

Figure 3: Kaplan-Meier plots of overall survival for GISTs grouped according to mitosis (A), Ki-67 proliferation index (B) and tumor size $(\mathbf{C})$. 


\section{DISCUSSION}

GISTs have a broad and divergent spectrum of biological behavior ranging from a benign to a malignant disease course. For many years, a variety of prognostic factors have been searched to predict these tumors' outcome. Fletcher et al. published the first risk classification system for GIST in 2002, which is currently named the National Institutes of Health (NIH) classification. Based on size and mitotic count in 50 high power fields (HPF), a four grade scale (very low risk, low risk, intermediate risk and high risk) to predict biological behavior was proposed (5). This classification system was employed in several studies (7-9). In 2006, Miettinen and Lasota proposed a new classification based on the evaluation of 1765 GISTs of the stomach and 906 GISTs of the small intestine, which is also known as the Armed Forces Institute of Pathology (AFIP) classification $(2-4)$. In this classification system, the anatomic site of the primary tumor was introduced as additional criteria in risk assessment (2-4). Several researchers evaluated $\mathrm{NIH}$ consensus criteria and proposed a revision of the AFIP criteria (9-11). Thereafter, in 2010, the first TNM classification of GIST was published, based on three major prognostic factors; site, size, and mitotic rate (12). Since then, numerous studies have been published about both the use of this risk category and additional prognostic parameters, predicting the clinical course of these tumors.

Tumor size and mitotic rate have been regarded as the most reliable parameters for determining prognosis by many authors (7-16). DeMatteo et al. mentioned that tumor size was a significant factor for an adverse outcome in their report involving 200 GISTs (14). Similarly, Miettinnen et al. have mentioned that tumors smaller than $2 \mathrm{~cm}$ have lower risk of progression in all locations, and tumors larger than $5 \mathrm{~cm}$ in the small intestine and greater than 10 $\mathrm{cm}$ at gastric sites were reported to be more aggressive in behavior $(3,7)$. However, they also emphasized that tumor size could not predict the prognosis by itself after detecting that tumors which were bigger than $10 \mathrm{~cm}$ concurrently with low mitotic activity have relatively better prognosis than same size tumors with high mitotic activity, in their report involving 1765 gastric GISTs (3). Likewise, in 2008, DeMatteo et al. emphasized that more than 5 mitoses per $50 \mathrm{HPF}$ and tumor size greater than $10 \mathrm{~cm}$ were the two significant independent factors that negatively influence disease-free survival (15). Similar to the literature, larger tumor size $(\geq 5 \mathrm{~cm})$ and higher mitotic index $(>5 / 50 \mathrm{HPF})$ were correlated with poor overall survival in our study.

As suggested by Miettinen, tumor localization is an important prognostic predictor in addition to tumor size and mitotic rate in GISTs (3, 15-19). Emory et al. reported that survival rates were worst for patients with small bowel GIST tumors and best for those with esophageal ones (19). Miettinnen (3) and Güler et al. (13) found that small intestine tumors had more aggressive behavior than tumors located in the stomach. DeMatteo et al. found that patients with large bowel GIST experienced a high rate of recurrence and only $20 \%$ were free of recurrence (15). In our study, similar to DeMatteo, large bowel location had the worst prognosis of all gastrointestinal localizations.

The Ki-67 proliferation index also appears to be another very important prognostic factor in GIST. In some reports, Ki-67 was considered as a good indicator of the risk of metastasis $(9,19,20)$. However there is controversy regarding the cut-off values for Ki-67 levels, methods of determination and its prognostic utility above the mitotic rate. Nilsson et al. identified maximum Ki-67 proliferative index $(\geq 5 \%)$ as one of two independent risk factors together with tumor size and they even proposed a two-tier risk scoring system based on both maximum tumor size and Ki-67 score (8). Nilsson et al. suggested that the Ki-67 proliferative index determined in "hot spots" has a stronger predictive value than the mitotic rate (8). Similarly, due to the difficulty of evaluating the mitotic count for quality of slides and differences in interpretation, other authors as Suster and Panizo-Santos et al. also suggested that the Ki67 index was a stronger prognostic indicator and superior to using the mitotic rate $(20,21)$. However, there are also studies of Rudolph et al. in which the mitotic index was seen as better predictive factor of prognosis (22). Similarly, Şahin et al. showed a direct association between higher mitotic count and low overall survival, but not with the Ki-67 proliferation index (23). In our study, a statistically significant association was found between mean survival and the Ki-67 proliferation index. The patients whose Ki-67 proliferation index was higher than $6 \%$ had shorter overall survival than patients whose proliferation index was lower than $6 \%$. We did not find any superiority of the mitotic rate and Ki-67 indexes to each other. However, we noted the significant relationship between both indexes in terms of survival.

Other prognostic parameters in patients with GISTs that are reported to influence overall survival negatively are male sex $(9,16)$, epithelioid cell component (16) and the presence of necrosis (13,24-26). Some authors did not find any relationship between either histological subtype and gender with survival (17). In our study, we noted the significant association between the presence of necrosis and overall survival. Although tumors with epithelioid 
cell morphology were found to be related with a lower mean survival ratio, this was not found to be statistically significant. The gender of patients also did not have any prognostic impact on survival in our study group.

The histopathological diagnosis of GIST requires immunohistochemical confirmation of CD 117 expression, with either a diffuse or membranous staining pattern. CD 117 protein reactivity is reported between $72-100 \%$ in different series $(3,16,25)$. CD 117 positivity was detected in $90.8 \%$ of our cases. The other immunohistochemical markers that are used for diagnosis and differential diagnosis of GISTs are SMA, desmin, CD 34 and S100. The frequency of SMA, desmin, CD 34 and S100 have been reported as $27-74 \%, 3-53 \%, 56-82 \%$ and $1-28 \%$ respectively in the literature $(3,16,25-27)$, and our results were similar. The frequency of CD 34 and SMA expression in GISTs varied depending on the site of occurrence $(3,7)$. While most esophageal and rectal GISTs are positive for CD 34, small intestinal tumors are often positive for SMA $(2,3,7)$. In our study, a statistically significant association was found for CD 34 expression between stomach and non-stomach tumors but CD 34 positivity was detected mostly in the stomach. However there were no statistically significant associations for CD 117, SMA, desmin and S100 expression between localizations. Fujimoto et al. considered positive S100 protein immunoreactivity to be significantly associated with a poor prognosis in GISTs (16). While Miettinen et al. reported that SMA and desmin positivity were prognostically favorable factors (7). In our study, CD 34 positivity was found to be related with higher overall survival but no significant association was found between overall survival and CD 117, SMA, desmin and S100 immunoreactivity.

In conclusion, the prediction of the clinical outcome of GISTs is often difficult. Therefore it is important to determine the pathological parameters that have an impact on prognosis. In this study, the Ki-67 proliferation index, the presence of necrosis, and the presence of metastasis were found to be related with poor prognosis in GISTs in addition to well-known predictive factors such as increasing tumor size and high mitotic activity.

\section{CONFLICT of INTEREST}

The authors declare no conflict of interest.

\section{REFERENCES}

1. Hamilton SR, Aaltonen LA. Tumours of the stomach in World Health Organization Classification of Tumours. Pathology and Genetics of Tumours of the Digestive system. Lyon: IARC Press; 2000:37-66.
2. Miettinen $M$, Lasota J. Gastrointestinal stromal tumors: Pathology and prognosis at different sites. Semin Diagn Pathol. 2006;23:70-83

3. Miettinen M, Sobin LH, Lasota J. Gastrointestinal stromal tumors of the stomach. A clinicopathologic, immunohistochemical, and molecular genetic study of 1765 cases with long-term follow-up. Am J Surg Pathol. 2005;29:52-68.

4. Miettinen M, Makhlouf H, Sobin LH, Lasota J. Gastrointestinal stromal tumors of the jejunum and ileum: A clinicopathologic, immunohistochemical, and molecular genetic study of 906 cases before imatinib with long-term follow-up. Am J Surg Pathol. 2006;30:477-89.

5. Fletcher CD, Berman JJ, Corless C, Gorstein F, Lasota J, Longley BJ, Miettinen M, O'Learly TJ, Remotti H, Rubin BP, et al. Diagnosis of gastrointestinal stromal tumors: A consensus approach. Hum Pathol. 2002;33:459-65.

6. Klieser E, Pichelstorfer $M$, Weyland D, Kemmerling $R$, Swierczynski S, Dinnewitzer A, Jager T, Kiesslich T, Neureiter D, Illig R. Back to start: Evaluation of prognostic markers in gastrointestinal stromal tumors. Mol Clin Oncol. 2016;4:763-73.

7. Miettinen M, Lasota J. Gastrointestinal stromal tumors: Review on morphology, molecular pathology, prognosis and differential diagnosis. Arch Pathol Lab Med. 2006;130:1466-78.

8. Nilsson B, Bümming P, Meis-Kindblom J.M, Oden A, Dortok A, Gustavsson B, Sablinska K, Kindblom LG. Gastrointestinal stromal tumors: The incidence, prevalance, clinical course, and prognostication in the preimatinib mesylate era- a populationbased study in western Sweden. Cancer. 2005;103:821-9.

9. Rutkowski P, Nowecki ZI, Michej W, Debiec-Rychter M, Wozniak A, Limon J, et al. Risk criteria and prognostic factors for predicting recurrences after resection of primary gastrointestinal stromal tumor. Ann Surg Oncol. 2007;14:2018-27.

10. Huang HY, Li CF, Huang WW, Hu TH, Lin CN, Uen YH, Hsiung CY, Lu D. A modification of NIH consensus criteria to better distinguish the highly lethal subset of primary localized gastrointestinal stromal tumors: A subdivision of the original high-risk group on the basis of outcome. Surgery. 2007;141:74856.

11. Goh BK, Chow PK, Yap WM, Kesavan SM, Song IC, Paul PG, Ooi BS, Chung YF, Wong WK. Which is the optimal risk stratification system for surgically treated localized primary GIST? Comparison of three contemporary prognostic criteria in 171 tumors and a proposal for a modified Armed Forces Institute of Pathology risk criteria. Ann Surg Oncol. 2008;15:2153-63.

12. Sobin LH, Gospodarowicz MK, Wittekind C. TNM Classification of malignant tumours. Oxford: Wiley-Blackwell; 2010.

13. Güler B, Özyılmaz F, Tokuç B, Can N, Taştekin E. Histopathological feautures of gastrointestinal stromal tumors and the contribution of DOG1 expression to the diagnosis. Balkan Med J. 2015;32:388-96.

14. DeMatteo RP, Lewis JJ, Leung D, Mudan SS, Woodruff JM, Brennan MF. Two hundred gastrointestinal stromal tumors: Recurrence patterns and prognostic factors for survival. Ann Surg. 2000;231:51-8. 
15. DeMatteo RP, Gold JS, Saran L, Gönen M, Liau KH, Maki RG, Singer S, Besmer P, Brennan MF, Antonescu CR. Tumor mitotic rate, size, and location independently predict recurrence after resection of primary gastrointestinal stromal tumor (GIST). Cancer. 2008;112:608-15.

16. Fujimoto Y, Nakanishi Y, Yoshimura K, Shimoda T. Clinicopathologic study of primary malignant gastrointestinal stromal tumor of the stomach, with special reference to prognostic factors:analysis of results in 140 surgically resected patients. Gastric Cancer. 2003;6:39-48.

17. Sözütek D, Yanık S, Akkoca AN, Sözütek A, Özdemir ZT, Avşar ÇU, Günaldı M, Sahin B, Doron F. Diagnostic and prognostic roles of DOG1 and $\mathrm{Ki}-67$, in GIST patients with localized or advanced/metastatic disease. Int J Clin Exp Med. 2014;7:1914-22.

18. Fu Y, Hao H, Guo L, Yang G, Zhnag X. Retrospective analysis of 85 cases of intermediate-risk gastrointestinal stromal tumor. Oncotarget. 2017;8:10136-44.

19. Emory TS, Sobin LH, Lukes L, Lee DH, O'Leary TJ. Prognosis of gastrointestinal smooth-muscle (stromal) tumors: Dependence on anatomic site. Am J Surg Pathol. 1999;23:82-7.

20. Suster S. Gastrointestinal stromal tumors. Semin Diagn Pathol. 1996;13:297-313.
21. Panizo-Santos A, Sola I, Vega F, de Alava E, Lozano MD, Idoate MA, Pardo-Mindán J. Predicting metastatic risk of gastrointestinal stromal tumors: Role of cell proliferation and cell cycle regulatory proteins. Int J Surg Pathol. 2000;8:133-44.

22. Rudolph P, Gloeckner K, Parwaresch R, Harms D, Schmidt D. Immunophenotype, proliferation, DNA ploidy, and biological behaviour of gastrointestinal stromal tumors: A multivariate clinicopathologic study. Hum Pathol. 1998;29:791-800.

23. Şahin S, Ekinci Ö, Seçkin S, Dursun A. The diagnostic and prognostic utility of DOG1 expression on gastrointestinal stromal tumors. Turk Patoloji Derg. 2017;33:1-8.

24. Shiu MH, Farr GH, Papachristou DN, Hajdu SI. Myosarcomas of the stomach: Natural history, prognostic factors and management. Cancer. 1982;49:177-87.

25. Newman PL, Wadden C, Fletcher CDM. Gastrointestinal stromal tumors:correlation of immunophenotype with clinicopathological features. J Pathol. 1991;164:107-17.

26. Franquement DW, Frierson HF. Muscle differentiation and clinicopathologic features of gastrointestinal stromal tumors. Am J Surg Pathol. 1992;16:947-54.

27. Miettinen M, Sobin LH, Sarloma-Rikala M. Immunohistochemical spectrum of GISTs at different sites and their differential diagnosis with a reference to CD 117 (KIT). Mod Pathol. 2000;13:1134-42. 